\title{
Morphology, composition and mixing state of individual carbonaceous aerosol in urban Shanghai
}

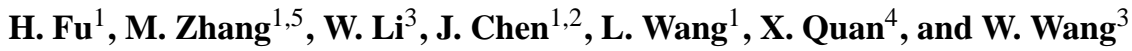 \\ ${ }^{1}$ Department of Environmental Science and Engineering, Fudan University, Shanghai 200433, China \\ ${ }^{2}$ Research Institute for the Global Environment Change, Fudan University, Shanghai 200433, China \\ ${ }^{3}$ Environment Research Institute, Shandong University, Jinan Shandong 250100, China \\ ${ }^{4}$ College of Environment and Life, Dalian University of Technology, Dalian Liaoning 116024, China \\ ${ }^{5}$ Key Laboratory of Data Analysis and Applications, The First Institute of Oceanography, State Oceanic Administration, \\ Qingdao, 266061, China
}

Correspondence to: J. Chen (jmchen@fudan.edu.cn)

Received: 25 May 2011 - Published in Atmos. Chem. Phys. Discuss.: 26 July 2011

Revised: 23 November 2011 - Accepted: 8 December 2011 - Published: 16 January 2012

\begin{abstract}
A total of 834 individual aerosol particles were collected during October and November 2010 in urban Shanghai, China. Particles were sampled under different weather and air quality conditions. Morphologies, compositions and mixing states of carbonaceous aerosols were investigated by transmission electron microscopy (TEM) coupled with energy-dispersive X-ray (EDX). Structures of some particles were verified using selected-area electron diffraction (SAED). Among the aerosol particles observed, carbonaceous aerosols were mainly categorized into four types: polymeric organic compound (POC), soot, tar ball, and biogenic particle. Based on the detailed TEM-EDX analysis, most of the particles were coated with secondary organic aerosols (SOA), which commonly formed through condensation or heterogeneous reactions of precursor gases on preexisting particles. Aged particles were associated with days with low wind velocities, showed complex structures, and were bigger in size. The internally mixed particles of sulphates, organics and soot were encountered frequently. Such internally mixed particles may be preferentially formed during a stagnated air mass during serious pollution events, such as on 13 November. Although relative number counts varied with different species, sulphates (38-71\%) and soot (11$22 \%$ ) constituted the most dominant species observed in the samples. However, soil-derived particles $(68 \%)$ were relatively more frequently observed on the sample collected on 12 November during a dust storm.
\end{abstract}

\section{Introduction}

Carbonaceous aerosols exert great influence on climate by changing the energy transfer through the atmosphere, and potentially affect public health as carriers of toxic chemicals (Jacobson, 2001; Ramana et al., 2010; Utsunomiya et al., 2002; Menon et al., 2002). Carbonaceous aerosols also supply surfaces for heterogeneous chemical reactions to occur upon in the atmosphere, and alter the regional biogeochemical cycle by their long-range transport with nutrient species (Adachi et al., 2010; Geng et al., 2010a; Ro et al., 2005; Utsunomiya et al., 2004). Generally, carbonaceous aerosols in ambient air are broadly differentiated into two main fractions: elemental carbon (EC) and organic carbon (OC). EC is often used interchangeably with black carbon (BC) in terms of light absorbing (Jacobson, 2001; Andreae and Gelencsér, 2006). OC in aerosols ranges from small molecules such as oxalic acids, to polycyclic aromatic hydrocarbons, to viable bacteria, fungi, and spores, to secondary OC aerosols formed initially by oxidation of volatile organics (Pan et al., 2007).

Carbonaceous aerosols have direct effects on climate by scattering and absorbing solar radiation. Soot particles produce a net warming effect through absorption of sunlight (Ramanathan et al., 2008). The IPCC report indicates that their global, annual mean clear-sky radiative forcing is approximately $0.34 \mathrm{Wm}^{-2}$, making them the largest contributor to global warming after carbon dioxide and methane (IPCC, 2007). In high pollution areas such as Mexico City and Beijing, much of the soot particles are embedded with OC together with materials such as ammonium sulphate 
(Adachi and Buseck, 2008; Li et al., 2010; Li and Shao, 2009a). These embedding materials and coatings act as lenses that focus light on soot and thus amplify absorption (Adachi et al., 2007). Jacobson (2001) suggests that internally mixed soot particles, commonly present in the atmosphere, could be the second most significant component of global warming. OC consists of primary organic aerosols and secondary organic aerosols, having highly variable optical properties. Light-absorbing organic aerosol is tentatively named "brown carbon" and may be associated with high molecular weight humic-like substances (HULIS) from biomass burning or soil deflation (Alexander et al., 2008; Hoffer et al., 2006). HULIS not only leads to the efficient absorption of solar radiation in the UV and visible range, but also exhibits much stronger wavelength dependence at shorter wavelengths than EC (Alexander et al., 2008). Atmospheric models of the climate effects of carbonaceous aerosols assume that no light-absorbing particles are produced in the air by secondary mechanisms. The main optical effect of light-coloured OC from secondary emission is thought to be scattering of sunlight, resulting in a net cooling effect on global climate (Chung and Seinfeld, 2002).

Besides, carbon-bearing particles can serve as cloud condensation nuclei $(\mathrm{CCN})$ and may affect the formation, coverage, and lifetime of clouds, thereby having an indirect effect on climate (Sun and Ariya, 2006). Recent studies on atmospheric aerosols have shown that OC aerosols are an important part of the global CCN budget. Their activation capability is assumed to be comparable to that of sulphate aerosols, which is considered the most effective CCN (Sun and Ariya, 2006). Both organic acids and HULIS have been identified as the predominant constituents of organic CCN (Sun and Ariya, 2006). Furthermore, OC aerosols can alter the hygroscopic properties and CCN activity of inorganic particles by their mixing states. Inorganic particles with hygroscopic OC coatings tend to be more spherical and larger and more hydrophilic, enhancing their light scattering and CCN activity, both of which have cooling effects on the climate (Freney et al., 2010; Semeniuk et al., 2007). Field measurements have shown that a significant fraction of both continental and marine inorganic aerosols are coated by organic films (Li et al., 2003a; Niemi et al., 2006; Russell et al., 2002). This widespread occurrence of mixed organic and inorganic species within the same particle implies a broad impact on the global radiation balance. BC may play an important, but as yet undetermined, role in the cloud formation processes. Decesari et al. (2002) reported that the soot oxidation process caused the formation of HULIS, which may be potential CCN precursors. The CCN ability of collapsed aged soot particles was further recognized by Zuberi et al. (2005) through laboratory studies. In light of these observations, Sun and Ariya (2006) speculated that the CCN activity of soot particles may not be neglected when considering their indirect radiative forcing.
Carbonaceous aerosol emissions in China are large and are estimated to account for around one-fourth of global anthropogenic carbonaceous aerosols (Menon et al., 2002; Zhou et al., 2009). Enhanced emissions due to the increased usage of fossil fuels, combined with biomass burning and soil dust, have been causing serious air pollution in urban areas and frequently extend to regional haze episodes ( $\mathrm{Li}$ et al., 2010; Li and Shao, 2009a, 2010). It was well known that carbonaceous particles emitted from intense biomass burning contribute significantly to the seasonal brown hazes in northern China (Li et al., 2010). Anthropogenic aerosols emitted from the developing megacities in China may have altered the regional atmospheric circulation, probably leading to increased summer flooding in the south and enhanced drought in the north (Menon et al., 2002). Clearly, a complete understanding of unique characteristics of anthropogenic aerosols, particularly carbonaceous aerosols, in the chemically rich atmosphere of China, must be conducted before the climate impacts of aerosols can be evaluated for China.

Our knowledge of Chinese urban aerosols is mostly indebted to extensive studies using bulk analysis methods. These studies have provided useful insights into the general characteristics of aerosols, including their concentrations, distributions and seasonal patterns (Zhou et al., 2009; Sun et al., 2006). However, urban aerosols are chemically and morphologically heterogeneous, so that the average composition does not describe well the population of the particles. Direct evidence of the composition and morphology of aerosol particles can be provided by single particle analysis (Geng et al., 2010b; Ro et al., 2005; Utsunomiya et al., 2004). The analytical TEM has been proven extremely useful for characterizing aerosols, especially for internally mixed particles, which is a unique source of information on particle coatings, agglomeration, and possible atmospheric reactions (Adachi et al., 2007; Freney et al., 2010). By using TEM techniques, Buseck et al. (2010) supplied visual evidence that the radiative property of soot was determined, to a large extent, by the mixing state of soot within individual particles, suggesting that the external mixing assumption is unrealistic for many atmospheric situations (Adachi et al., 2008, 2010; Frency et al., 2010). Based on the work of Buseck's group, we can suppose that the core-shell model used in current studies does not properly represent the shapes of ambient soot particles. Very recently, Pósfai and Buseck (2010) reviewed the results of individual particle studies that use microscopy-based techniques, emphasizing TEM and focusing on achievements of the past ten years.

Shanghai is an international metropolis near the East China Sea with a population of over 18 million $\left(31^{\circ} 23^{\prime} \mathrm{N}\right.$, $121^{\circ} 48^{\prime} \mathrm{E}$ ), which is home to China's largest petrochemical complex, steel makers, incinerators, and a seaport. The large usage of coal and biofuel burning, the increasing number of automobiles, rapid urbanization, and flourishing construction activities are all causing the high aerosol loadings (Gao et al., 2009; Ramana et al., 2010; Zhou et al., 2009). 
These factors make Shanghai air pollution difficult to control (Fu et al., 2008). To date, carbonaceous aerosols emitted from Shanghai are still not well known, especially by single particle analysis, although they may have a significant impact on not only air quality of Yangtze River Delta but also climate changes of east China. Toward this end we have employed the TEM-EDX technique to characterize carbonaceous aerosols in Shanghai. High-angle annular darkfield scanning transmission electron microscopy (HAADFSTEM) was used to create maps of element distributions of a single particle, and chemical inhomogeneities can be visualized within complex particles. We expected to gain insight into their formation and sources on local, regional, and long-range levels, and to possibly make a contribution to the determination of the impact of these aerosols on regional air pollution in east China.

\section{Experimental}

\subsection{Sampling}

Overall, 4 sets of aerosol samples were collected during October and November of 2010 at Fudan University $\left(31^{\circ} 18^{\prime} \mathrm{N}\right.$, $121^{\circ} 29^{\prime}$ E), Shanghai, China (Fig. 1). The sampling site is located on the rooftop of a five-storey building (about $20 \mathrm{~m}$ above the ground) on the campus. The buildings surrounding the sampling site mostly consist of commercial properties and residential dwellings. An incineration facility (Jiangqiao) with a capacity of $1500 \mathrm{td}^{-1}$ is situated $13 \mathrm{~km}$ west. Further into Shanghai's industrial Boshan district, some $20 \mathrm{~km}$ north of the site, are several power plants with capacities over $1200 \mathrm{MW}$. Another one (Yuqiao), located $16 \mathrm{~km}$ to the south of the site, could process 1200 tons of solid waste per day. Apart from the point sources, vehicular traffic may also have affected the measurements made at the study site. There is a local road (Guoding road) with light traffic $300 \mathrm{~m}$ east of the observation site, and a heavily trafficked road (central ring road) is about $150 \mathrm{~m}$ south of the site. The site at Fudan University can be treated as a representative urban site influenced by a mixture of emission sources, but not dominated by any one source.

Particles were collected onto the 300-mesh copper TEM grids coated with carbon films using a single-stage cascade impactor with a 0.5 -mm-diameter jet nozzle with a flow rate of $1.01 \mathrm{~min}^{-1}$. The sampler has a collection efficiency of $100 \%$ at $0.5 \mu \mathrm{m}$ aerodynamic diameter if the density of the particles is $2 \mathrm{~g} \mathrm{~cm}^{-3}$. More information about the sampler can be found elsewhere (Li et al., 2010; Li and Shao, 2010). The grids contain fiber-like carbon substrates that minimize particle overlap, and TEM images show well-separated individual particles (Fig. S1). Sampling periods ranged between 30 to $180 \mathrm{~s}$, depending on particle loading. The collected samples were put in plastic carriers, sealed, and stored in a desiccator to minimize exposure to ambient air and preserve them for further analysis.

Measurements of wind speed/direction, relative humidity, and ambient temperature were automatically recorded by a Kestral 4000 Pocket Weather Tracker (Nielsen-Kellermann Inc., USA), as shown in Fig. S2. $\mathrm{O}_{3}$ was measured by pulsed UV fluorescence (Thermo Fisher Scientific, Co., Ltd., Model 49 i). $\mathrm{NO}_{\mathrm{x}}$ was measured by a molybdenum $\mathrm{NO}_{2}$-toNO converter using the chemiluminescent reactions (Thermo Fisher Scientific, Co., Ltd., Model 42i). Visibility, air pollution index (API), and mass concentrations of $\mathrm{SO}_{2}$ and $\mathrm{PM}_{10}$ were provided by Shanghai Meteorological Bureau. All this information is shown in Table 1. A Wide-Range Particle Spectrometer (WPS ${ }^{\mathrm{TM}}$, MSP Corporation model 1000XP) was used to measure size distributions in the range of 0.01$10 \mu \mathrm{m}$. The instrument is an aerosol spectrometer that combines the principles of Differential Mobility Analyser (DMA), Condensation Particle Counter (CPC) and Laser Particle Spectrometer (LPS) (Gao et al., 2009). Mass size distributions in this work were calculated by assuming an apparent particle density to be $1 \mathrm{~g} \mathrm{~cm}^{-3}$ and particles to be spherical shaped. A model ADI 2080 online analyzer for Monitoring of Aerosols and Gases (MARGA, Applikon Analytical B.V. Corp., the Netherlands) with a particulate matter sampler $\left(\mathrm{PM}_{2.5}\right)$ was used to measure mass concentrations of major water-soluble inorganic ions in aerosols $\left(\mathrm{NH}_{4}^{+}, \mathrm{Na}^{+}\right.$, $\mathrm{K}^{+}, \mathrm{Ca}^{2+}, \mathrm{Mg}^{2+}, \mathrm{SO}_{4}^{2-}, \mathrm{NO}_{3}^{-}$, and $\left.\mathrm{Cl}^{-}\right)$with one hour resolution (Du et al., 2010).

Backward air mass trajectories were produced using the Hybrid Single-Particles Lagrangian Integrated Trajectory (HYSPLIT4) model available at the NOAA/ARL's (US National Oceanic and Air Administration/Air Resources Laboratory) web server. The Final Run (FNL) meteorological data were used for the trajectory calculation (Draxler and Hess, 1998).

\subsection{TEM analysis}

The TEM grid samples were examined with a JEOL-2100F field emission high-resolution transmission electron microscope (FE-HRTEM) equipped with an Oxford EDX, a scanning TEM unit with a HAADF detector. The TEM was operated on an accelerating voltage of $200 \mathrm{kV}$. The distribution of aerosol particles on the TEM grids was not uniform. Coarser particles were deposited near the centers of the grids and finer particles on the periphery. Outward from the grid centers, the particles are more sparsely distributed. Because of the manual, labour-intensive operation of the TEM, only limited numbers of particles could be analyzed. To ensure that the analyzed particles were representative of the entire size range, three to four areas were chosen from the center and periphery of the sampling spot on each grid. The size of each particle was calculated using the best fitting ellipse to a particle outline, and the diameter of each particle was 

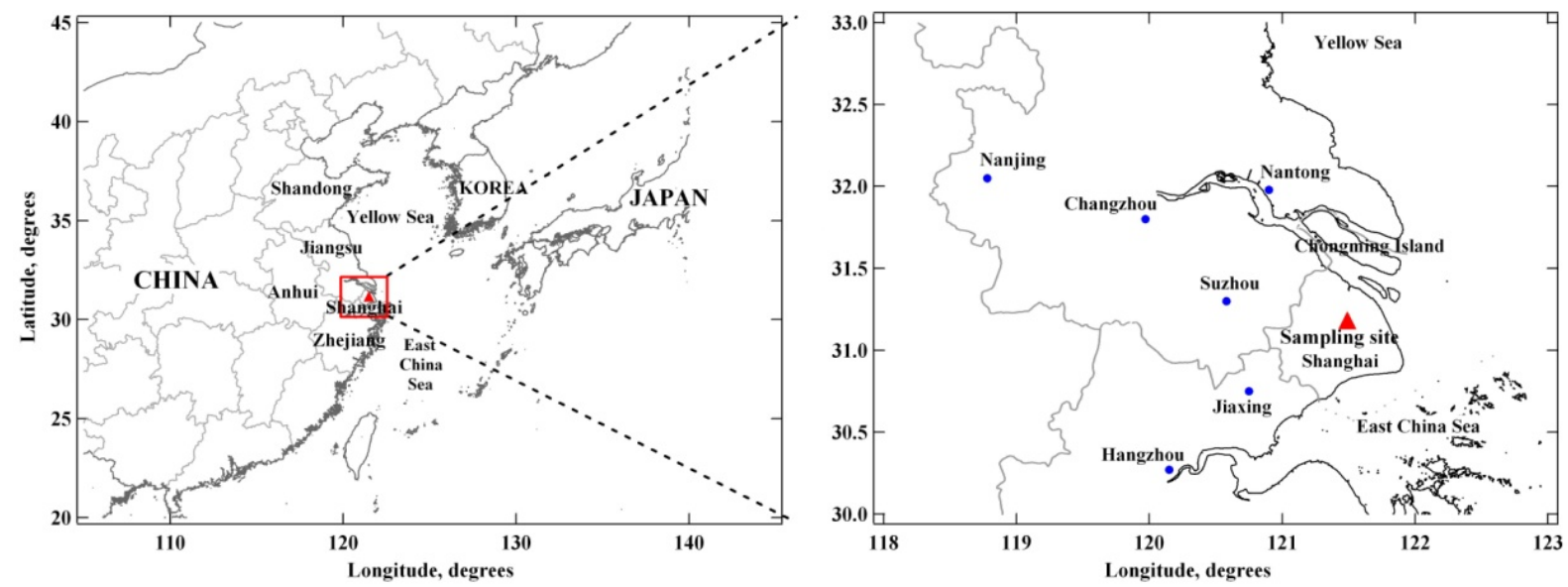

Fig. 1. Schematic map of sampling site.

Table 1. Sampling date, meteorological conditions, and daily averaged concentrations of atmospheric pollutants.

\begin{tabular}{|c|c|c|c|c|c|c|c|c|c|c|c|c|}
\hline \multirow[b]{2}{*}{ No. } & \multirow[b]{2}{*}{ Sampling Date } & \multirow[b]{2}{*}{$\begin{array}{l}\text { Start of } \\
\text { Sampling }\end{array}$} & \multirow[b]{2}{*}{$T\left({ }^{\circ} \mathrm{C}\right)$} & \multirow[b]{2}{*}{$\mathrm{RH}(\%)$} & \multirow[b]{2}{*}{$\begin{array}{c}\mathrm{WS} \\
\left(\mathrm{m} \mathrm{s}^{-1}\right)\end{array}$} & \multirow[b]{2}{*}{ WD } & \multirow[b]{2}{*}{$\begin{array}{l}\text { Visibility } \\
(\mathrm{km})\end{array}$} & \multirow[b]{2}{*}{$\begin{array}{c}\mathrm{O}_{3} \\
\text { (ppbv) }\end{array}$} & \multicolumn{4}{|c|}{ Daily averaged concentrations } \\
\hline & & & & & & & & & API* & $\begin{array}{c}\mathrm{SO}_{2} \\
\left(\mu \mathrm{g} \mathrm{m}^{-3}\right)\end{array}$ & $\begin{array}{c}\mathrm{NO}_{\mathrm{x}} \\
\left(\mu \mathrm{g} \mathrm{m}^{-3}\right)\end{array}$ & $\begin{array}{c}\mathrm{PM}_{10} \\
\left(\mu \mathrm{g} \mathrm{m}^{-3}\right)\end{array}$ \\
\hline 1 & 15 Oct 2010 & $15: 00$ & $22.3-23.7$ & $53-57$ & $0-3.7$ & $\mathrm{NE}$ & 15 & $23.8-43.6$ & 71 & 22 & 78 & 92 \\
\hline 2 & 12 Nov 2010 & $15: 00$ & $15.3-15.5$ & $62-66$ & $1.3-7.0$ & SW & 5 & $14.0-66.0$ & 298 & 365 & 107 & 418 \\
\hline 3 & 13 Nov 2010 & $15: 00$ & $17.3-17.5$ & $87-89$ & $0-1.9$ & SE & 10 & $42.7-51.0$ & 370 & 225 & 88 & 476 \\
\hline 4 & 24 Nov 2010 & $15: 00$ & $14.4-14.9$ & $57-59$ & $0-6.2$ & NE & 27 & $2.0-9.0$ & 51 & 10 & 74 & 52 \\
\hline
\end{tabular}

*Air Pollution Index (API, API = 100 corresponds to Chinese air quality standard II).

calculated as the arithmetic mean of the short and long axes of the ellipse ( $\mathrm{Li}$ and Shao, 2010).

Elemental compositions were determined semiquantitatively by using an energy-dispersive X-ray spectrometer (EDX) that can detect elements heavier than carbon. EDX spectra were recorded in TEM image mode and then quantified using ES Vision software that uses the thin-foil method to convert X-ray counts of each element into atomic or weight percentages. EDX were collected for $30 \mathrm{~s}$ in order to minimize radiation exposure and potential beam damage. Electron diffraction patterns of the crystalline phases were recorded in SAED. EDX, SAED and HRTEM were conducted on some of the same particles. EDX spectra provided information on chemical compositions, while SAED and HRTEM were used to examine the structure of crystalline particles. The X-ray counts from carbon coating of TEM grids were estimated by analysing blank areas between particles. The net X-ray counts of each particle analysed were calculated, and their proportions were normalized to $100 \%$. Copper was not considered because of interferences from the copper TEM grid. Elemental mapping on some typical particles was conducted using HAADF-STEM with an EDX mapping system (Emispec, ES Vision ver. 4.0) on a micrometer scale.
Decomposition of the particles in the vacuum or under the electron beam further complicates EDX analyses. Changes in the TEM are visible, and a low-intensity electron beam was used to avoid decomposition during spectrum acquisition. Tar balls, soot particles, and biogenic particle did not show any changes in the beam, whereas the organic coatings and the internally mixed particles containing sulphates invariably changed under the electron beam; an analysis of such particles indicates the composition of the residue after the majority of the particle evaporated. In general, even where the EDX results may not accurately reflect original particle compositions, the analyses show characteristic changed between groups of particle types and from specimen to specimen, and thus useful for distinguishing certain groups of particles and for studying the trends of changes.

The strong vacuum $\left(\sim 10^{-7}\right.$ torr $)$ and beam exposure causes evaporation of semivolatile compounds from particles, and for that reason, water, ammonium nitrate and semivolatile organic compounds were lost, as is typical in electron microscopy (Niemi et al., 2006). Particles examined by TEM were dry at the time of observation, although some may have been droplets in the atmosphere because of the high relative humidity in the environment. Ammonium sulphate particles probably crystallized on the TEM grids. Therefore, the morphologies of some aerosol particles, as 
observed in the TEM, may differ from their shapes prior to collection ( $\mathrm{Li}$ et al., 2003a). Despite possible changes in morphology, and except for volatile species, the compositions of the particles measured herein should reflect their original compositions before collection. It should be noted that the upper limits of the resulting size distributions may be affected by the inhomogeneous distribution of particles on the grids, because some large particles pile up in the center, where particle overlap makes size measurements impossible. On the other hand, the lower ends of the size distributions may have been affected by poor collection efficiency of $<100 \mathrm{~nm}$ particles on the TEM grids (Pósfai et al., 2003).

\section{Results and discussion}

\subsection{Air quality and meteorology during sampling periods}

The samples were collected on 15 October, 12 November, 13 November, and 24 November, with corresponding API daily averages of 71, 298, 370 and 51, respectively (Table 1). According to National Ambient Air Quality Stand (NAAQS) in China, two heavily polluted days occurred on 12 November and 13 November. The daily average concentrations of inhalable particles $\left(\mathrm{PM}_{10}\right)$ were 418 and $476 \mu \mathrm{g} \mathrm{m}^{-3}$ on 12 November and 13 November, respectively, nearly 3 times higher than Grade (II) of NAAQS in China $\left(150 \mu \mathrm{g} \mathrm{m}^{-3}\right)$. $\mathrm{PM}_{10}$ concentrations on 15 October and 24 November were much lower than Grade (II) of NAAQS while a bit higher than Grade (I) of NAAQS $\left(50 \mu \mathrm{g} \mathrm{m}^{-3}\right)$; therefore, they were considered as "two moderate days".

To better understand the sources of the particulate matter during sampling, we computed the backward air trajectories at three altitudes of 200,500 and $1000 \mathrm{~m}$ above ground level (AGL), and the results are shown in Fig. 2. It is clear that the air masses on 12 November (Fig. 2b) originated from Mongolia, then passed through the desert and the semi-desert regions in western Inner Mongolia, carrying high concentrations of dust particles, and finally reached Shanghai along a northwest direction within 3 days (Fig. 2b). The air masses at $500 \mathrm{~m}$ and $1000 \mathrm{~m}$ fell and moved very slowly when they arrived at Shanghai, and may impact the ground-level air quality in Shanghai. The air masses on 13 November (Fig. 2c) mainly originated from Jiangshu and Anhui provinces, and arrived at Shanghai from the direction of the East China Sea. The air masses at $200 \mathrm{~m}$ on both 24 November (Fig. 2d) and 15 October (Fig. 2a) originated from Shandong and Bo Sea, both of which have a long distance to pass over the Yellow Sea before arriving at Shanghai.

The obvious increase of the particle mass concentrations in the size range $1 \sim 10 \mu \mathrm{m}$ in Fig. $3 \mathrm{a}$ and $\mathrm{b}$ illustrates the occurrence of a dust storm in Shanghai after 00:00 local time (LT) on 12 November. With the given assumption, the maximum mass concentration of the dust particles observed was approximately $250 \mu \mathrm{g} \mathrm{m}^{-3}$, and the particles with $D_{\mathrm{p}}>1 \mu \mathrm{m}$ accounted for more than $90 \%$ of the total mass concentrations which only accounted for around $35 \%$ in the day before 12 November, indicating that the coarse mode increased greatly when the dust storm approached the sampling site and that the total particle mass was dominated by the coarse mode during the storm period. After 10:00 LT on 13 November, the influence of the dust storm became less important and the coarse mode of the mass-concentration distributions diminished.

The concentrations of water-soluble ions in $\mathrm{PM}_{2.5}$ provided the additional proof for the dust event on 12 November (Fig. 4). $\mathrm{Mg}^{2+}$ and $\mathrm{Ca}^{2+}$ were mainly from crustal sources, such as resuspended road dust, soil dust, and construction dust, and $\mathrm{SO}_{4}^{2-}, \mathrm{NO}_{3}^{-}$, and $\mathrm{NH}_{4}^{+}$represented the secondary pollution sources from the transformation of their precursors of $\mathrm{SO}_{2}$ and $\mathrm{NO}_{2}$ (Hwang et al., 2008; Jeong, 2008; Sun et al., 2006). The concentrations of $\mathrm{Mg}^{2+}$ and $\mathrm{Ca}^{2+}$ at 00:00 LT on 12 November increased gradually and peaked at 08:00 LT on 12 November. The peak values of $\mathrm{Mg}^{2+}$ and $\mathrm{Ca}^{2+}$ during the dust storm were 0.6 and $7 \mu \mathrm{g} \mathrm{m}^{-3}$, respectively, which were about 10 and 14 times higher than 00:00 LT on 11 November (the day before the dust storm). The concentrations of $\mathrm{SO}_{4}^{2-}, \mathrm{NO}_{3}^{-}$and $\mathrm{NH}_{4}^{+}$decreased by a factor of 1.6-4.7 times from $9.5,12.1$, and $7.1 \mu \mathrm{g} \mathrm{m}^{-3}$ to $6.0,5.3$, and $1.5 \mu \mathrm{g} \mathrm{m}^{-3}$, respectively, which could be the dilution effect of the dust storm. Variations of water-soluble ions were consistent with the backward trajectory analysis and the meteorological conditions.

\subsection{Major type and microstructure of carbonaceous aerosol}

Here, we put more emphasis on carbonaceous aerosols collected from the urban Shanghai atmosphere, since they are the major fraction of the aerosols by number in urban atmosphere, and are hence relevant for studying radiative effects and CCN properties of aerosols (Zhou et al., 2009; Ramana et al., 2010). Based on their morphologies and X-ray spectral data, carbonaceous aerosol occurring in the samples were categorized into the following four types: (1) polymeric organic compound, (2) soot, (3) tar ball, and (4) biogenic particle. It must be noted that, since many different types of internally mixed particles were identified, for clarity, the particles were grouped according to chemical species with the highest content present in the particles. Based on this criterion, the particles with organic coating were not listed as a separate type of carbonaceous aerosol, and will be discussed later in detail.

\subsubsection{Polymeric organic compounds (POCs)}

The bulk of particles were that the sum of the $\mathrm{C}$ and minor $\mathrm{O}$ and/or $\mathrm{N}$ contents was more than $90 \%$ in atomic fraction based on X-ray spectral data. Such particles ranged in 

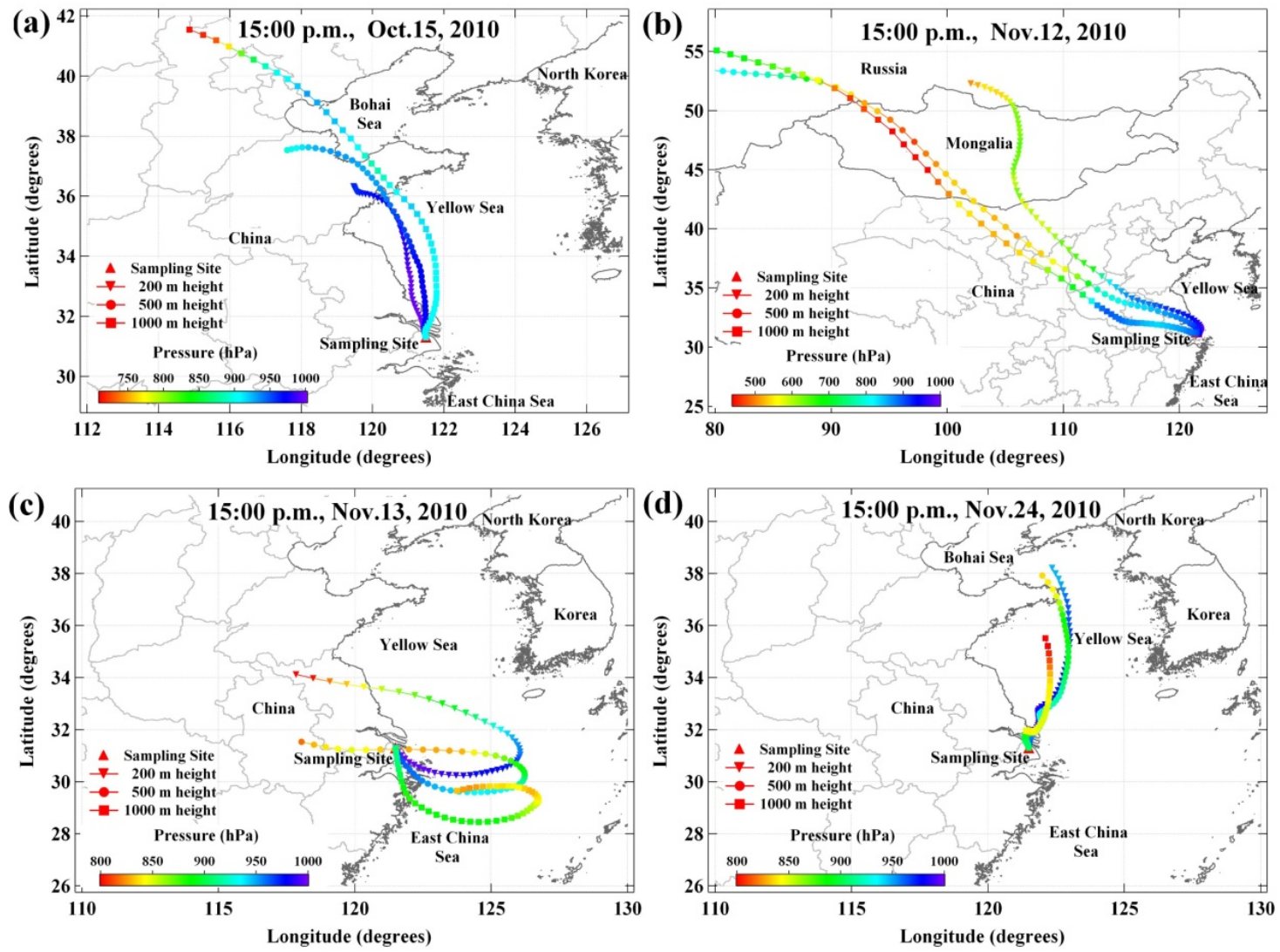

Fig. 2. The backward air-mass trajectories ending at $200 \mathrm{~m}, 500 \mathrm{~m}$ and $1000 \mathrm{~m}$ for (a) 15 October 2010 (48 h), (b) $12 \mathrm{November} 2010$ (72 h), (c) 13 November 2010 (48 h) and (d) 24 November 2010 (48 h) with the pressure indicated by colour-coded line.

diameter from $200 \mathrm{~nm}$ to $1.5 \mu \mathrm{m}$. They typically displayed rounded, relatively non-descript shapes, as shown in Fig. 5. Since EDX analyses only gave elemental compositions, we had not direct evidence that $\mathrm{C}$ in these particles occurred in organic compounds. However, it was widely assumed that all of EC in the tropospheric aerosols was within soot particles (Jacobson, 2001). Because these particles lacked the typical concentrically stacked graphitic layers of soot, we assumed they consisted of organic substances. Unlike organic coating (will be discussed in the Sect. 3.3.1), POCs were not beam sensitive and did not evaporate under prolonged exposure to the electron beam, as indicated by a couple of TEM analysis. Such insusceptibility against the electron beam lead to the hypothesis that POCs may be high-molecule organic compounds, such as HULIS (polycyclic aromatic hydrocarbons), which has been hypothesized to form from the incomplete breakdown of polymeric carbohydrates in the atmosphere (Alexander et al., 2008; Hoffer et al., 2006). HRTEM (the inset of Fig. 5d) exhibited completely amorphous structure of the POCs. In this work, we defined these particles as POCs.

Most of POCs contain soil-like elements such as $\mathrm{Al}, \mathrm{Mg}$, $\mathrm{Si}$, and Ca. Particularly, they were coated or embedded with Si-rich particles (Fig. 5a and b). It has been reported that many soil-derived aluminosilicate particles contained carbonaceous species that probably come from humic substances in soil (Geng et al., 2010; Jeong, 2008; Ro et al., 2001). Si-rich particle is the most common mineral in soils but can also form during fossil fuel combustion processes (Li and Shao, 2009b). However, soil-derived Si-rich particles formed by mechanical processes are irregularly shaped. Fly ash particles produced during high-temperature combustion are typically spherically shaped (Geng et al., 2010). This type of POCs was encountered more frequently in the sample of 12 November, collected during a dust storm event. Some of POCs contained $\mathrm{K}$, in addition to $\mathrm{Cl}, \mathrm{S}$ and $\mathrm{Si}$ (Fig. 5d and e). The potassium enrichment in aerosols has been used as a fingerprint of their biomass-burning origin (Pósfai et al., 2003, 2004; Li et al., 2003b). Previous field-measurements have proposed that biomass burning was an important origin of HULIS in East Asia (Alexander et al., 2008; Hoffer et al., 2006). POCs were often found to be coated by S- or N-rich rim (Fig. $5 \mathrm{c}$ and d), indicating that they were readily oxidized by common atmospheric gases such as $\mathrm{NO}_{\mathrm{x}}$ and $\mathrm{SO}_{2}$. Figure 5f shows a typical POC particle with S-rich coating. Cube-like aggregated crystals (arrowed) indexed by the inset fast Fourier transform (FFT) pattern as $\mathrm{CaSO}_{4}$. 

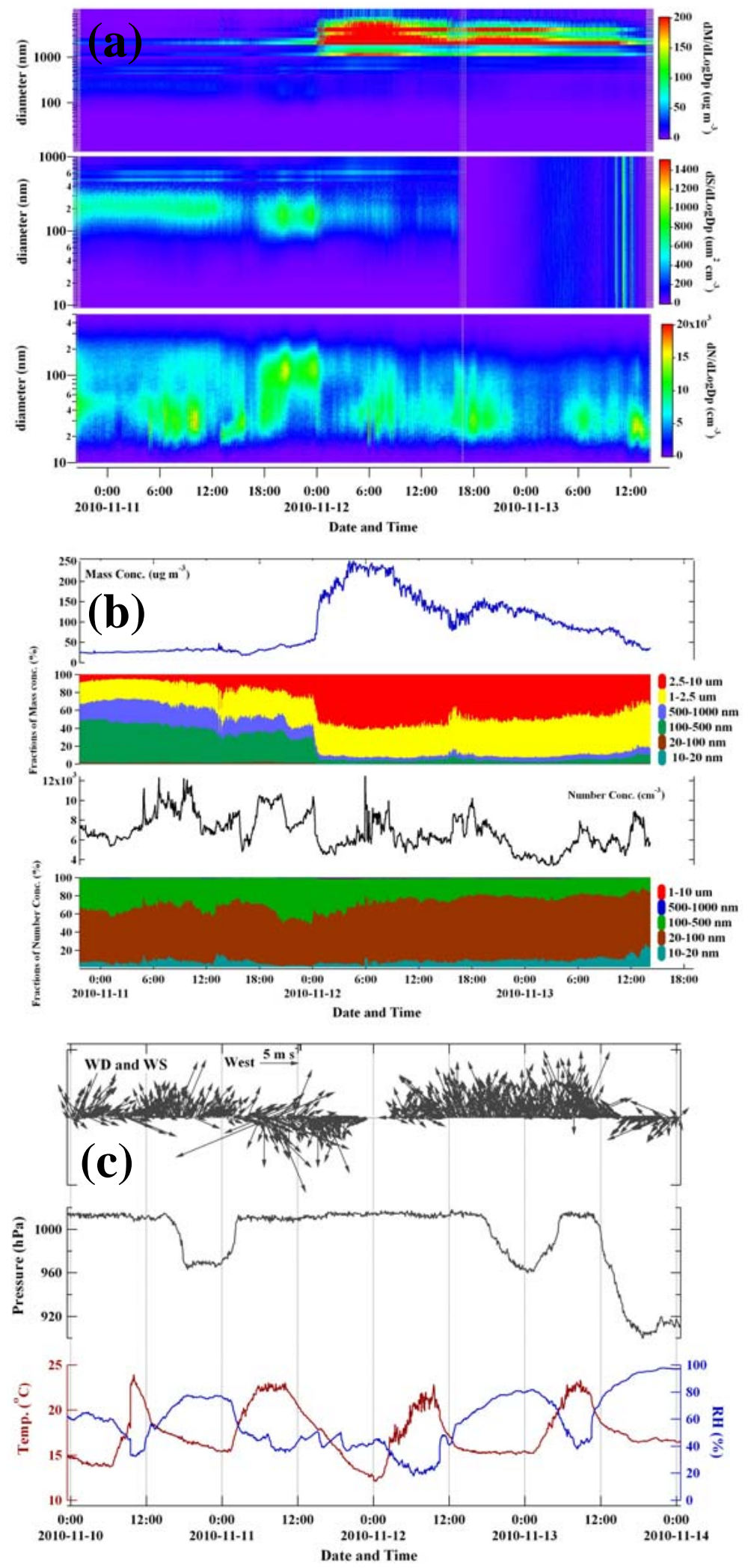

Fig. 3. The pollution event, 12-13 November 2010: (a) time series of mass, surface and number size distribution, (b) the average fractions of the particle mass and number concentrations in different size ranges, $(\mathbf{c})$ hourly meteorological data $(\mathrm{WD}=$ wind direction, WS $=$ wind speed, $\mathrm{RH}=$ relative humidity). 


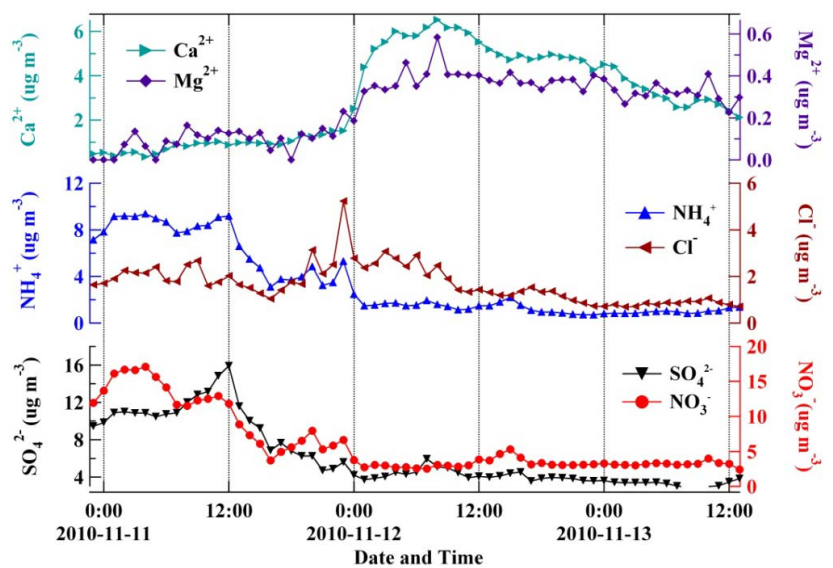

Fig. 4. Hourly concentrations of $\mathrm{Ca}^{2+}, \mathrm{Mg}^{2+}, \mathrm{HN}_{4}^{+}, \mathrm{Cl}^{-}, \mathrm{SO}_{4}^{2-}$, and $\mathrm{NO}^{3-}$ during the dust-haze episode (12-13 November 2010).

\subsubsection{Soot}

Soot was common in all samples, which was believed to be formed via a vaporization-condensation mechanism during combustion processes (Chen et al., 2005, 2006a; Li et al., 2003b). Typical soot aggregate has spherical primary particles and fractal-like chain structures that can extend to a couple of micrometers or more (Fig. 6a and e). HRTEM image of the soot spheres shows onion-like structures of curved, disordered graphitic layers (Fig. 6d). STEM-EDX mapping shows that the soot aggregate mostly contained $\mathrm{C}$ and, to a lesser extent, $\mathrm{O}$ (Fig. $6 \mathrm{~b}$ and c). Typical SAED patterns of soot aggregates (Fig. 6g) exhibited three distinct rings, which were indexed to the crystalline structure of graphite (Viktória et al., 2006). The SAED pattern obtained from soot aggregates shows broad and diffuse 002 and hk rings, indicating a microstructure consisting of randomly distributed crystallites that had a fine size and did not possess long range order, which was consistent with the previous study (Chen et al., 2005). Dark-field image (Fig. 6f) was used to visualize individual microcrystallites. The bright spots in the darkfield image were produced by diffraction from the 002 planes of microcrystallites. These bright spots were distributed unevenly within the particles. Such patterns observed could be due to a different density of circumferential 002 lattice planes parallel to the electron beam (Chen et al., 2005; Viktória et al., 2006).

Besides the major component of $\mathrm{C}$ and $\mathrm{O}$, soot may also contain variable, trace amounts of $\mathrm{S}, \mathrm{K}, \mathrm{Si}, \mathrm{Ca}, \mathrm{Fe}, \mathrm{Mn}$ and $\mathrm{Zn}$. These external inorganic species may constitute an important fingerprint that could be used to identify their possible combustion and fuel sources (Chen et al., 2005). The type of the soot aggregates shown in Fig. 6a often contained trace $\mathrm{K}$ element, suggesting the soot aggregate with larger particles was most likely originated from biomass burning. The soot aggregates with smaller primary particles often

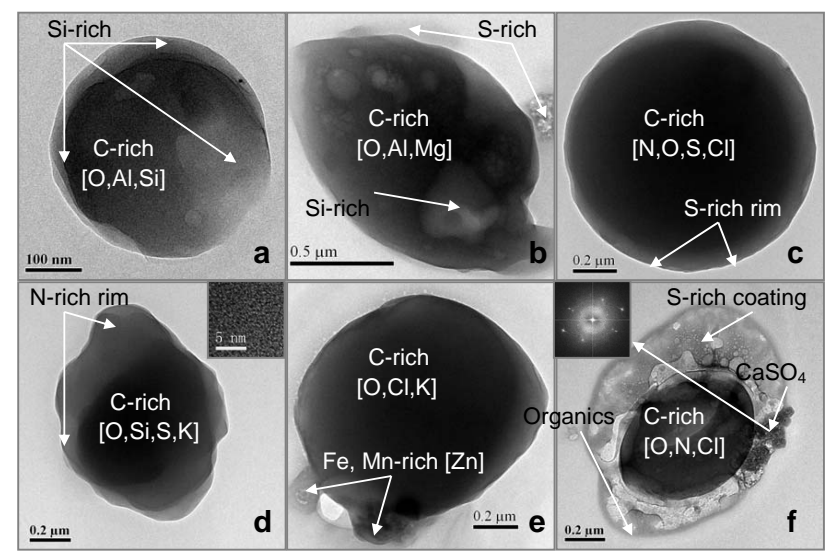

Fig. 5. TEM images of the typical POC particles collected from the atmosphere of Shanghai. Element of the detected parts of individual particles is mainly $\mathrm{C}(>80 \%)$, and minor elements are indicated in square brackets. (a) C-rich particle coated by Si-rich layer. (b) Crich particle internally mixed with Si-rich. (c) C-rich particle with $\mathrm{S}$-rich rim. (d) $\mathrm{C}$-rich particle with $\mathrm{N}$-rich rim. HRTEM image in the inset shows amorphous microstructures of the particle bulk. (e) C-rich particle is attached to two metal-bearing particles (Fe, Mn, $\mathrm{Zn}$ ). (f) C-rich particle with S-rich coating, surrounded by organic layer. Cube-like aggregated crystals (arrowed) indexed by the inset FFT pattern as $\mathrm{CaSO}_{4}$.

exhibited trace $\mathrm{Si}$ and $\mathrm{Ca}$, which may originate from vehicle exhaust since $\mathrm{Si}$ can be found in the fuel, and $\mathrm{Ca}$ is a frequent additive in oil (Kocbach et al., 2005; Vernooij et al., 2009). It has been reported that the smaller diameters of primary particles from vehicle exhaust could be due to the higher flame temperatures for engines (approximately $2000^{\circ} \mathrm{C}$ ) (Kocbach et al., 2005). Trace Fe ingredient, often coupled with Mn and $\mathrm{Zn}$ in soot aggregates, may be used as indicators for coal combustion (Chen et al., 2005). Soot aggregates exhibiting a discernible $\mathrm{S}$ have previously been observed from the atmosphere of Kentucky, which were prominently derived from the combustion of coal and residual oil (Chen et al., 2006b). However, the $\mathrm{S}$ tracer was present in almost all of soot aggregates in our samples, indicating the S-content in soot aggregates might be due to a reaction with ambient air rather than a source difference.

Some of the soot particles showed a modified morphology, which most likely resulted from atmosphere aging (Fig. 6h and i). Once emitted into the air, the irregular geometry and complex microstructure of soot aggregates may provide active sites for deposition of common atmospheric gases such as $\mathrm{O}_{3}, \mathrm{NO}_{2}$, and $\mathrm{SO}_{2}$, which could readily oxidize soot surfaces (Decesari et al., 2002). The soot- $\mathrm{O}_{3}$ reaction is particularly rapid, and prolonged exposure to ozone under laboratory conditions may lead to the collapse of the graphitic structure (Zhang et al., 2008). 


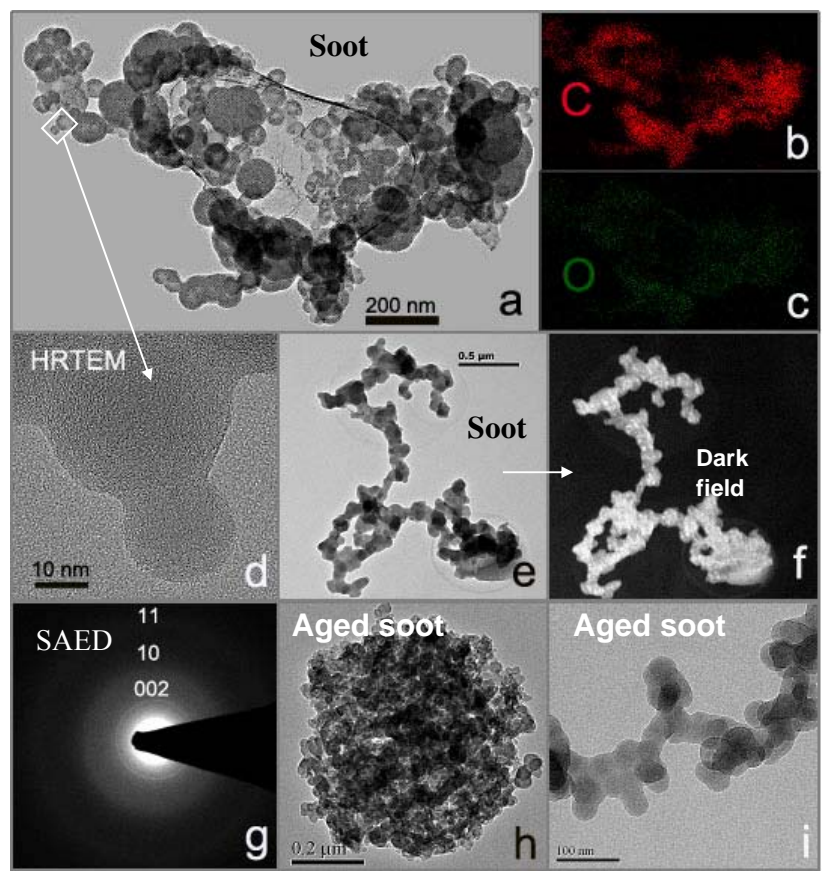

Fig. 6. TEM images of soot particles collected from the atmosphere of Shanghai. (a) The aggregate of chain-like soot particles with particle sizes $\left(D_{\mathrm{p}}>100 \mathrm{~nm}\right.$ or $\left.D_{\mathrm{p}}<80 \mathrm{~nm}\right)$. Elemental profiles obtained from STEM-EDS (HADDF-STEM mode) across the whole aggregate show the distribution of $\mathrm{C} \mathrm{(b)} \mathrm{and} \mathrm{O}(\mathbf{c})$ elements. (d) High-resolution TEM shows the soot spheres with onion-like curved, disordered graphitic (graphene layers). Bright-field image (e) and corresponding 002 dark-field image (f) of a soot aggregate with homogeneous size $\left(D_{\mathrm{p}}<80 \mathrm{~nm}\right)$. (g) Typical SAED pattern of the soot particle exhibits three distinct rings, corresponding to 002 , 10 and 11. (h) and (i) aged soot.

\subsubsection{Tar ball}

Tar balls were readily recognized in TEM images (Fig. 7a and b) by their spherical shape, which are produced by a gas-to-particle transformation followed by condensational growth in biomass smoke (Hand et al., 2005; Pósfai et al., 2003). Tar balls had a diameter range from $100-500 \mathrm{~nm}$ with a few particles larger than $1 \mu \mathrm{m}$. HRTEM images (Fig. 7c) of tar balls did not indicate any semiordered graphitic microstructure typical of soot. Their EDX spectra indicated elemental compositions consisting of $\mathrm{C}$ and $\mathrm{O}$ with trace amounts of $\mathrm{S}, \mathrm{K}, \mathrm{Cl}$ and $\mathrm{Si}$. Internal mixing of tar balls with other particle types was rarely observed.

In contrast to other widespread and spherical aerosol particle types, such as sulphate and K-rich particles, tar balls were stable and did not change visibly under prolonged exposure to the electron beam, suggesting they were composed of refractory material. It has been reported that the chemical compositions, densities, and carbon functional groups of tar balls were distinctly different from soot and black carbon and more closely resembled high molecular weight
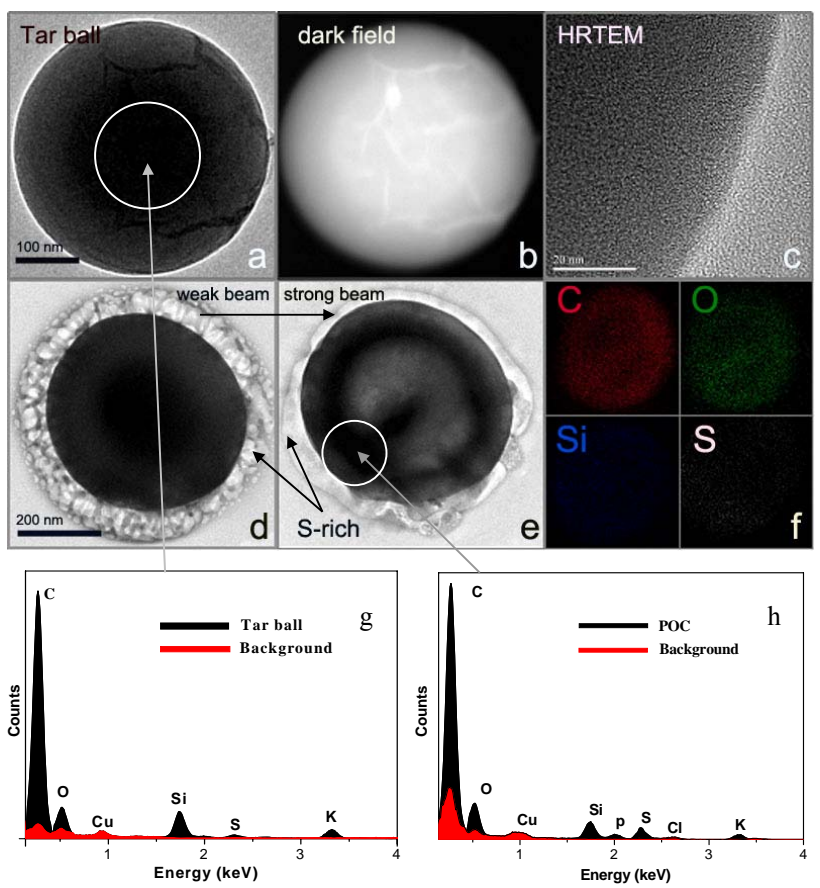

Fig. 7. TEM images of a typical spherical tar ball particle from a bright-field (a) and dark-field (b). HRTEM image of the same particle shows amorphous microstructures (c). A POC particle with sulphate-containing coating (d). The same particle expose to the strong beam (e). STEM-EDX maps showing the distributions of carbon element, oxygen element, silicon element, and sulphur element in the aged tar ball (f). EDX ( $\mathbf{g}$ and $\mathbf{h}$ ) recorded from the corresponding regions of white circles. The tar ball and a POC particle show similar element component $(\mathrm{C}, \mathrm{O}, \mathrm{Si}$, and $\mathrm{K}$ elements), but varied ratios.

polymeric humic-like substances, which could account for their reported optical properties (Pósfai et al., 2004; Li et al., 2003b).

Of special interest was to compare tar ball with $\mathrm{K}$ containing POCs (as noted previously), both of which showed similar element compositions with comparable amounts, amorphous microstructures, overlapped sizes, and strong resistances against electron bombardment. Since Pósfai et al. (2003) proposed that tar balls were probably correspond to an intermediate stage in the aging of organic particles from biomass burning, we strongly suspected that a fraction of K-containing POCs could be originated from tar balls. A typical POC particle with S-rich coating is shown in Fig. 7d. When exposed to electron beam, surface sulphates sublimated when the particle was exposed to electron beam (Fig. 7e). Element maps proved that $\mathrm{C}, \mathrm{O}$, and $\mathrm{Si}$ elements homogeneously distribute within the bulk of the particle. Homogeneous internal distributions of $\mathrm{C}$ and $\mathrm{O}$ in tar balls were previously reported (Hand et al., 2005). Also, our assumption was supported by a few field studies performed on southern Africa and California (Hand et al., 2005; Pósfai et al., 2003, 2004). Both tar balls and the organic particles with 


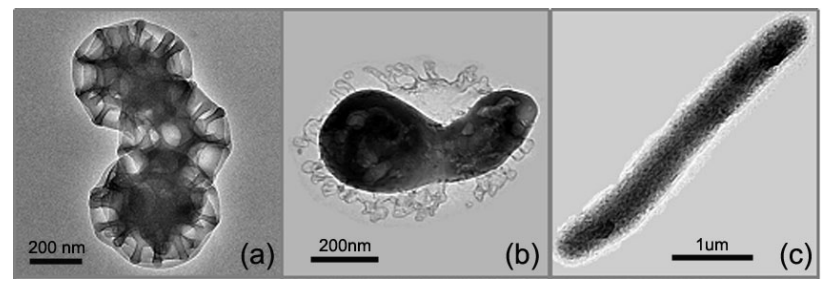

Fig. 8. TEM images of particles classified as biological particles. (a) Agglomerate of three brocosomes produced by leaf-hopping insects as a water-repellent body coat; (b and $\mathbf{c}$ ) unidentified biogenic particles in the present study.

minor $\mathrm{K}, \mathrm{Cl}$, and $\mathrm{S}$ contents were characteristic products in aged biomass plumes. Given the small number of particles analyzed in this study, it was difficult to evaluate the validity of this scenario, but it was certain that both K-containing POCs and tar balls observed in the atmosphere of Shanghai come from biomass burning.

\subsubsection{Biogenic particle}

Biogenic particles are a special type of organic particles with special morphologies, ranging in size from millimeters down to tens of nanometers. The number concentrations of biogenic particles range from minor fractions of the total aerosol in oceanic $(1 \%)$ and continental $(2 \%-3 \%)$ settings, to $\sim 25 \%$ in a continental aerosol and $35 \%$ in Amazonia (Wittmaack et al., 2005). The simultaneous presence of minor $\mathrm{N}, \mathrm{P}, \mathrm{S}, \mathrm{Si}$ and $\mathrm{Cl}$ with $\mathrm{C}$ and $\mathrm{O}$ was considered as "biogenic fingerprint" in the previous studies (Geng et al., 2010b; Pósfai and Buseck, 2010; Niemi et al., 2006). Most biological particles originate from terrestrial plants, while the ocean with the "bubble-burst" mechanism is also an important producer (Wittmaack et al., 2005). In this work, biogenic carbonaceous particles have also been observed in the urban air of Shanghai. Figure 8 shows the TEM images of several typical biogenic particles. The morphology of these particles varied strongly from simple bar to complicated biological structures. The HRTEM image exhibited completely amorphous structure.

Particles having interesting, flower-like morphologies with diameters around $400 \mathrm{~nm}$, occurred in the sample collected 15 October (Fig. 8a). They contained mostly of $\mathrm{C}$ and $\mathrm{O}$ and also contained significant $\mathrm{Si}$, which was believed to serve as a highly water repellent body coating of leafhoppers (Pósfai et al., 2010). They might originate mainly from local forests. Leafhopper is a common insect in Shanghai, and widely distributed in east China. Particles with similar morphologies and compositions were observed in other geographically diverse regions, such as southern Africa, Munich and Kentucky (Pósfai et al., 2003, 2010; Chen et al., 2005).

\subsection{Mixing states of carbonaceous particles and formation mechanisms}

\subsubsection{Particles with organic coatings}

Several TEM studies have shown the inorganic particles with organic coating were widespread in urban atmosphere (Adachi and Buseck, 2008; Li and Shao, 2010). Similar results were well observed in our samples. Most of the particles, including S-rich particles, fly ashes, mineral dusts and metal-rich particles were coated with a carbonaceous film, and a few typical particles with organic coating are shown in Fig. 9a-c. Similar particles, with coatings of various thickness of organic coating, have been widely observed in a variety of samples, including those from pristine marines and polluted continental environments (Adachi and Buseck, 2008; Li and Shao, 2010; Russell et al., 2002; Niemi et al., 2006). Organic coatings were lost under strong beam bombardment. It was believed that organic coating was composed of second organic aerosol (SOA), which commonly forms through condensation of precursor gases on pre-existing particles such as soot, ammonium sulphate (Fan et al., 2006). The high ozone and VOC concentrations in urban Shanghai atmosphere suggested that the formation of SOA and their subsequent condensation may be a significant pathway in the formation of organic coating. Previous studies have suggested that ozone, hydroxyl radical, nitrate radical, and other oxidants presented during atmospheric transport played a central role on the formation of SOA in Beijing atmosphere (Li and Shao, 2010). In Shanghai, about half of VOCs come from motor vehicles, and $10 \sim 35 \%$ of VOCs was from industrial activities, indicating the organic coating in these aerosol particles were likely formed by VOCs from fuel combustion, and a lesser extent from industrial activities (F. Geng et al., 2009). Tar balls were an indicator of biomass and biofuel burning (Hand et al., 2005; Pósfai et al., 2004). The low abundance of tar balls indicated little influence from biomass burning on the formation of organic coating (see the Sect. 3.4). Laboratory experiments have found that SOA is slightly hygroscopic and exhibits a smooth water uptake with increasing the particle sizes (Varubangkul et al., 2006). Therefore, the circle stamps in the grid indicate that their organic coatings likely held water before they was sampled, suggesting the formation of such coating by aqueous-phase processing of the particles during transport in atmosphere. Organic coatings could modify the particle hygroscopicity, CCN abilities and heterogeneous chemical reactivity, indicating that the ubiquitous presence of this particle type in urban Shanghai atmosphere had important ramifications of the regional climate (Adachi et al., 2008; Russell et al., 2002; Li et al., 2003a). 


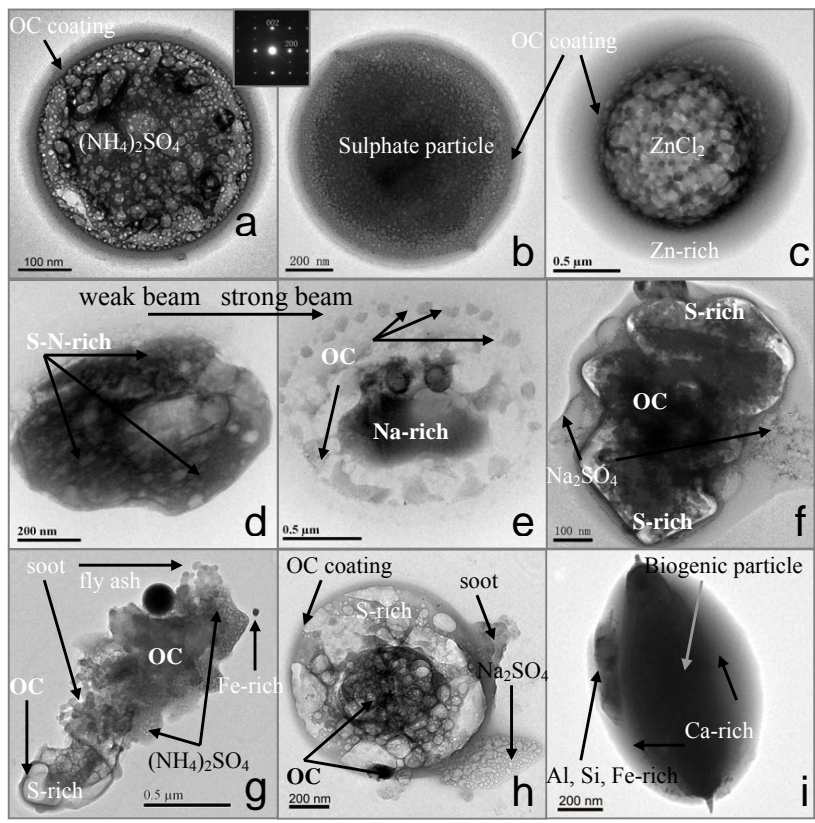

Fig. 9. TEM images of the typical C-bearing particles collected from the atmosphere of Shanghai. (a) An ammonium sulphate particle with organic coating. The inset is the diffraction pattern of ammonium sulphate. The diffraction pattern was obtained from a similar-looking particle, which was destroyed during electron-beam exposure. (b) Biogenic particle coated by thin organic layer. (c) $\mathrm{ZnCl}_{2}$ particle with organic coating (arrowed), and then encapsulated in the Zn-rich layer. (d) Organic components embedded in the $\mathrm{N}$-S-rich particle. (e) The exposed organic components from decomposition of the beam-sensitive NS- rich particle. (f) The internally mixed organic/sulphate-containing particles (ammonium sulphate) after intentional strong beam exposure. The SAED image and EDS show the basis for the identification of the bar-shaped particles (arrowed) as $\mathrm{Na}_{2} \mathrm{SO}_{4}$. (g), and (h) the internally mixed particles containing soot, organic matter and sulphates. (i) Biogenic particle attached with Ca-rich material.

\subsubsection{Internally mixed particles}

S-rich particles, likely ammonium sulphate, dominated in most of samples. In TEM images, these particles were euhedral or rounded. Most particle diameters were $<500 \mathrm{~nm}$ or from $800 \mathrm{~nm}$ to $1.5 \mu \mathrm{m}$. Close examination of TEM-EDX showed that many of the ammonium sulphate grains consisted of organic components, which exhibited carbon peaks higher than those seen from background. The sulphates readily decomposed when exposed to an electron beam (Fig. 9df). When decomposing, they left a similar carbonaceous residue. Laboratory studies showed that sulphate nucleation was often coupled with aromatic acids (Zhang, 2004); thus, it was not surprised that organics were present in small sulphate particles. A smaller size of the sulphate grains seemed homogeneous and were commonly coated by organic layer, while the larger ones were commonly internally mixed with soot and organic matter (or more chemical species) (Fig. 9g and h). Within the internally mixed particles, most of organics may be beam-sensitive SOA (Fig. 9d and e), consistent with the usual findings that SOA was coupled with S-rich particles (Kanakidou et al., 2005). However, some particles also contained beam-resistant dark inclusions without clear morphological characteristics, which may be POCs, collapsed soot or tar ball. Previous water dialysis experiments of individual particles have demonstrated that the coatings were water soluble, while organic inclusions were insoluble ( $\mathrm{Li}$ and Shao, 2010).

Such internally mixed particles may be preferentially formed in an aerosol mass stagnates, which often occurs during episodes of serious pollution (such as urban haze) when there is insufficient wind velocity to carry pollutants away from the city. During these periods of pollutant retention, aerosols continue to collide and combine with each other, resulting in larger average sizes and complex components. Larger sizes are commonly associated with polluted environment and adverse meteorological conditions (Li et al., 2010). In high pollution areas such as Mexico City, over half of the aerosol particles consist of internally mixed soot, organic matter, and sulphates (Adachi and Buseck, 2008). Sulphate coatings can have either negative or positive effects on the radiative forcing of $\mathrm{BC}$. On one hand, the internally mixed sulphates can make organic matter and soot more hydrophilic and eventually make them efficient scatters of solar radiation and CCN. While, on the other hand, embedding sulphates act as lenses that focus light on soot and thus amplify absorption of the internally particles (Adachi and Buseck, 2008; Adachi et al., 2010).

\subsubsection{Aged biogenic particles}

The aged biogenic particles were relatively frequently observed in both clean and polluted environments (Fig. S3). The particles shown in Fig. 8a commonly embedded in or aggregated with soot aggregates, but still retain their whole flower-like morphology. The surface of the aged particles changed apparently under electron bombardment, suggesting that they may be coated by sulphates (Fig. S3d and e). The attached sulphates could affect the hygroscopicity of the particles, favouring the activation to $\mathrm{CCN}$. Previous studies have reported that biogenic particles may act as $\mathrm{CCN}$ and play an important role for the long-range transport of trace elements into and away from specific biomes (Witmaack et al., 2005).

\subsection{Relative abundances and possible sources}

Figure 10 shows the relative number percentages of major chemical species in the samples collected at different times. Although there was a variation in the relative number counts of different species, sulphates ( $15 \%-71 \%$ ), followed by soot (7\%-22\%), constituted the most dominant species observed 
(a)

Oct.15, 2010: 213 particles

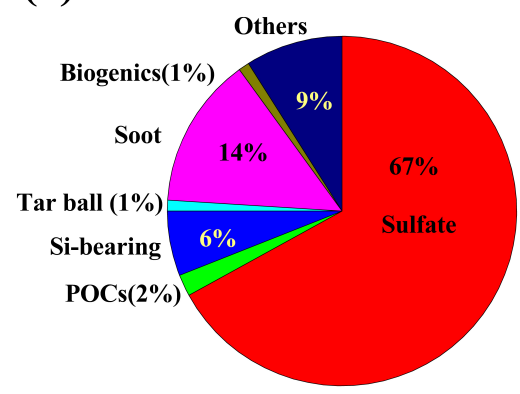

(c)

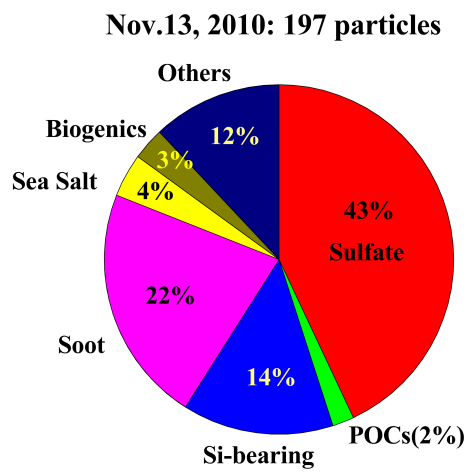

(b)

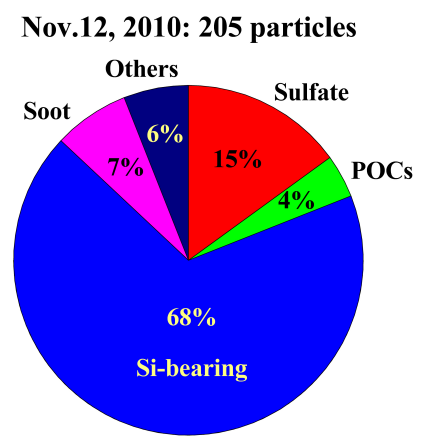

(d)

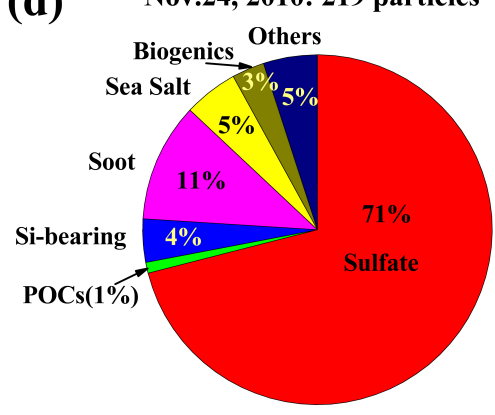

Fig. 10. The relative number percentages of major chemical species in the samples collected at Shanghai: (a) 15 October 2010, (b) 12 November 2010, (c) 13 November 2010, and (d) 24 November 2010.

in the samples. The sulphur in these particles was probably present mainly as ammonium sulphate salts, because most of the particles did not have satellite droplet rings around them, which is characteristic of $\mathrm{H}_{2} \mathrm{SO}_{4}$ particles ( $\mathrm{Li}$ et al., 2010; Zhang et al., 2000). The high concentrations of $\mathrm{SO}_{4}^{2-}$ and $\mathrm{NH}_{4}^{+}$measured by ion chromatography also supported the dominance of ammonium sulphate salts (not shown). In urban areas, it is well-known that ammonium sulphate particles are major chemical species, which are mostly from the reaction of atmospheric $\mathrm{SO}_{2}$ with $\mathrm{NH}_{3}$ under high relative humidity (Zhang et al., 2000; Geng et al., 2010; Chen et al., 2006). Particles containing abundant ammonium sulphate species, either as single species or mixed with others, been frequently observed in Mexico City, Kentucky, and Qingdao (Adachi and Buseck, 2008; Chen et al., 2006; Zhang et al., 2000). The carbonaceous particles comprise mostly soot aggregates, which is consistent with the previous observations of urban atmosphere (Adachi and Buseck, 2008; Chen et al., 2006). Urban areas generally undergo high loads of carbonaceous particles from heavy traffic, emissions from industrial plants, and intensive energy consumption. Previous work has demonstrated the poor correlation between $\mathrm{BC}$ and $\mathrm{SO}_{2}$ in Shanghai, suggesting that diesel vehicles are the dominant sources of BC (Zhou et al., 2009). Only minor tar balls were present in the samples; the low abundance of these particles indicated biomass burning was not a main source of $\mathrm{BC}$ during sampling.
As shown in Table 1, the API values of 13 November, 24 November, and 15 October are 370, 51 and 71, with the wind speeds of $0-1.9,0-6.2$, and $0-3.7 \mathrm{~m} \mathrm{~s}^{-1}$, respectively. Pollutant concentrations in Shanghai were greatly influenced by weather conditions, especially wind speeds. Strong negative correlation between average wind speeds and pollutant concentrations was found in Shanghai ( $R^{2}$ of 0.74$)$, when significant wind speed changes existed (Feng et al., 2006). On 13 November, the high pollution was related to low wind speeds of $0-1.9 \mathrm{~m} \mathrm{~s}^{-1}$ from southeast direction. This suggested that the main sources of pollutants were local in Shanghai. The larger sizes of internally mixed particle, often containing soot, sulphates and organic matters, were more common in the sample of 13 November as compared to the samples of 24 November and 15 October, suggesting the weather condition did not favour dispersion and transport of air pollutants, resulting in more collisions, combinations and coagulations among particles, and thus more complex morphologies and larger sizes of aerosols.

Specifically for the sample collected on 12 November, soil derived particles were more abundant $(68 \%)$ as compared to sulphates $(15 \%)$ and soot $(7 \%)$. That does not hold for the other samples, in which sulphate were predominant. The backward air mass trajectories showed that the air masses originated from Mongolia and Gobi desert of China, which belonged to typical source regions of Asian dust storm. On one hand, local pollutants will be diluted by 
long-range transport of dust plumes. On the other hand, the formation of ammonium sulphate/bisulphate might be suppressed as sulphuric acid was taken up by mineral particles with basic surfaces (Ro et al., 2005; H. Geng et al., 2009). Both of them lead to much lower contents of soot $(7 \%)$ and sulphates $(15 \%)$ in the sample of 12 November as compared to the other samples. On the basis of the back-trajectories, the air-mass fell and moved very slowly when they arrived at Shanghai, suggesting that dust particles had a chance to mix with local pollutants for the reactions. TEM-EDX analysis showed that most mineral particles, especially those particles with small size, presented N-rich or S-rich coatings. It was reported that Asian dust storm events provided a removal mechanism for $\mathrm{NO}_{\mathrm{x}}\left(\right.$ or $\left.\mathrm{HNO}_{3}\right)$ and perhaps contributed to nitrogen deposition in the Yellow Sea and the eastern China Sea (H. Geng et al., 2009; Zhang et al., 2010).

\section{Conclusions}

In this study, individual aerosol in the urban atmosphere of Shanghai were observed using TEM-EDX. Several types of carbonaceous particles were present in our aerosol samples, which were POC, soot, tar ball, and biogenic particle. Organic coating, commonly formed through condensation of precursor gases on pre-existing particles, was also widely observed in the most samples. Soot $(11 \%-22 \%)$ constituted the most dominant carbonaceous species observed in the samples. Soil-derived POCs particles were relatively more frequently observed during the dust storm. During the polluted day, most carbonaceous particles were in aggregates, which had a significant influence on their physical and chemical properties and may change their radiative properties and thus their climatic effects. Aged particles were associated with days with low wind velocities, showed complex structures, and were bigger in size.

\section{Supplementary material related to this article is available online at: http://www.atmos-chem-phys.net/12/693/2012/ acp-12-693-2012-supplement.pdf.}

Acknowledgements. We gratefully acknowledge the NOAA Air Resources Laboratory (ARL) for the provision of the HYSPLIT transport model used in this publication. Thank Shanghai Meteorological Bureau for providing meteorological data. Financial support was provided by National Natural Science Foundation of China (Nos. 40975074, 21177026, 21077025, 40875073); the Pujiang Talent Program of Shanghai, the Key Laboratory of Industrial Ecology and Environmental Engineering, China. Ministry of Education and Science \& Technology Commission of Shanghai Municipality (Nos. 09160707700, 10231203801, 10JC1401600).

Edited by: A. B. Guenther

\section{References}

Adachi, K. and Buseck, P. R.: Internally mixed soot, sulfates, and organic matter in aerosol particles from Mexico City, Atmos. Chem. Phys., 8, 6469-6481, doi:10.5194/acp-8-6469-2008, 2008.

Adachi, K. and Buseck, P. R.: Hosted and free-floating metalbearing atmospheric nanoparticles in Mexico City, Environ. Sci Technol., 44, 2299-2304, 2010.

Adachi, K., Chung, S. H., Friedrich, H., and Buseck, P. R.: Fractal parameters of individual soot particles determined using electron tomography: Implications for optical properties, J. Geophys. Res., 112, D14202, doi:10.1029/2006JD008296, 2007.

Adachi, K., Chung, S. H., and Buseck, P. R.: Shapes of soot aerosol particles and implications for their effects on climate, J. Geophys. Res., 115, D15206, doi:10.1029/2009JD012868, 2010.

Alexander, D. T. L., Crozier, P. A., and Anderson, J. R.: Brown carbon spheres in east Asian outflow and their optical properties, Science, 321, 833-836, 2008.

Andreae, M. O. and Gelencsér, A.: Black carbon or brown carbon? The nature of light-absorbing carbonaceous aerosols, Atmos. Chem. Phys., 6, 3131-3148, doi:10.5194/acp-6-3131-2006, 2006.

Chen, Y., Shah, N., Braun, A., Huggins, F. E., and Huffman, G. P.: Electron microscopy investigation of carbonaceous particulate matter generated by combustion of fossil fuels, Energ. Fuel., 19, 1644-1651, 2005.

Chen, Y., Shah, N., Huggins, F. E., and Hoffman, G. P.: Microanalysis of ambient particles from Lexington, KY, by electron microscopy, Atoms. Environ., 40, 651-663, 2006a.

Chen, Y., Shah, N., Huggins, F. E., and Huffman, G. P.: Microanalysis of ambient particles from Lexington, KY, by electron microscopy, Atmos. Environ., 40, 651-653, 2006b.

Chung, S. H. and Seinfeld, J. H.: Global distribution and climate forcing of carbonaceous aerosols, J. Geophys. Res., 107, 4407, doi:10.1029/2001JD001397, 2002.

Decesari, S., Facchini, M. C., Matta, E., Mircea, M., Fuzzi, S., Chughtai, A. R., and Smith, D. M.: Water soluble organic compounds formed by oxidation of soot, Atmos. Environ., 36, 1827 1832, 2002.

Draxler, R. R. and Hess, G. D.: An overview of the HYsplit-4 modeling system for trajectories, dispersion, and deposition, Aust Meteorol. Mag., 47, 295-308, 1998.

Du, H., Kong, L., Chen, J., and Cheng, T.: Insights into ammonium particle-to-gas conversion: non-sulphate ammonium coupling with nitrate and chloride, Aerosol Air Qual. Res., 10, 589595, 2010.

Fan, J., Zhang, R., Collins, D., and Li, G.: Contribution of secondary condensable organics to new particles formation: A case study in Houston, Texas, Geophys. Res. Lett., 33, L15802, doi:10.1029/2006GL026295, 2006.

Feng, J., Hu, M., Chan, C. K., Lau, P. S., Fang, M., He, L., and Tang, X.: A comparative study of the organic matter in $\mathrm{PM}_{2.5}$ from three Chinese megacities in three different climatic zones, Atmos. Environ., 40, 3983-3994, 2006.

Freney, E. J., Adachi, K., and Buseck, P. R.: Internally mixed atmospheric aerosol particles: Hygroscopic growth and light scattering, 115, D19210, doi:10.1029/2009JD013558, 2010.

Fu, Q., Zhuang, G., Wang, J., Xu, C., Huang, K., Li, J., Hou, B., Lu, T., and Streets, D. G.: Mechanism of formation of the heav- 
iest pollution episode ever recorded in the Yangtze River Delta, China, Atmos. Environ., 42, 2023-2026, 2008.

Gao, J., Wang, T., Zhou, X., Wu, W., and Wang, W.: Measurement of aerosol number size distributions in the Yangtze River delta in China: formation and growth of particles under polluted conditions, Atmos. Environ., 43, 829-836, 2009.

Geng, F., Zhang, Q., Tie, X., Huang, M., Ma, X., Dong, Z., Qiong, Y., Quan, J., and Zhao, C.: Aircraft measurements of $\mathrm{O}_{3}, \mathrm{NO}_{\mathrm{X}}$, $\mathrm{CO}$, VOCs, and $\mathrm{SO}_{2}$ in the Yangtze River Delta region, Atoms. Environ., 43, 584-593, 2009.

Geng, H., Park, Y., Hwang, H., Kang, S., and Ro, C.-U.: Elevated nitrogen-containing particles observed in Asian dust aerosol samples collected at the marine boundary layer of the Bohai Sea and the Yellow Sea, Atmos. Chem. Phys., 9, 6933-6947, doi:10.5194/acp-9-6933-2009, 2009.

Geng, H., Ryu, J.-Y., Jung, H.-J., Chung, H., Ahn, K.-H., and Ro, C.-U.: Single-particles characterization of summertime Arctic aerosols collected at Ny-Ålesund, Svalbard, Environ. Sci. Technol., 44, 2348-2353, 2010a.

Geng, H., Kang, H., Jung, J., Choel, M., Kim, H., and Ro, C.-U.: Characterization of individual submicrometer aerosol particles collected in Incheon, Korea, by quantitative transmission electron microscopy energy-dispersive X-ray spectrometry, J. Geophys. Res., 115, D15306, doi:10.1029/2009JD013486, 2010 b.

Gi, Y.-J.: Bulk and single-particle mineralogy of Asian dust and a comparison with its source soils, J. Geophys. Res., 113, D02208, doi:10.1029/2007JD008606, 2008.

Hand, J. L., Malm, W. C., Laskin, A., Day, D., Lee, T., Wang, C., Carrico, C., Carrillo, J., Cowin, J. P., Collett, J., and Ledema, M. J.: Optical, physical, and chemical properties of tar balls observed during the Yosemite Aerosol Characterization Study, J. Geophys. Res., 110, D21210, doi:10.1029/2004JD005728, 2005.

Hoffer, A., Gelencsér, A., Guyon, P., Kiss, G., Schmid, O., Frank, G. P., Artaxo, P., and Andreae, M. O.: Optical properties of humic-like substances (HULIS) in biomass-burning aerosols, Atmos. Chem. Phys., 6, 3563-3570, doi:10.5194/acp-6-3563-2006, 2006.

Hwang, H., Kim, H., Ro, C.-U.: Single-particle characterization of aerosol samples collected before and during an Asian dust storm in Chuncheon, Korea, Atmos. Environ., 42, 8738-8746, 2008.

IPCC: available at: http://www.ipcc.ch/publications_and_data/ar4/ syr/en/contents.html, 2007.

Jacobson, M. Z.: Strong radiative heating due to the mixing state of black carbon in atmospheric aerosols, Nature, 409, 695-697, 2001.

Kanakidou, M., Seinfeld, J. H., Pandis, S. N., Barnes, I., Dentener, F. J., Facchini, M. C., Van Dingenen, R., Ervens, B., Nenes, A., Nielsen, C. J., Swietlicki, E., Putaud, J. P., Balkanski, Y., Fuzzi, S., Horth, J., Moortgat, G. K., Winterhalter, R., Myhre, C. E. L., Tsigaridis, K., Vignati, E., Stephanou, E. G., and Wilson, J.: Organic aerosol and global climate modelling: a review, Atmos. Chem. Phys., 5, 1053-1123, doi:10.5194/acp-5-1053-2005, 2005.

Kis, V. K., Pósfai, M., and Labar, J. L.: Nanostructure of atmospheric soot particles, Atmos. Environ., 40, 5533-5542, 2006.

Kocbach, A., Johansen, B. V., Schwarze, P. E., and Namork, E.: Analytical electron microscopy of combustion particles: a comparison of vehicle exhaust and residential wood smoke, Sci. Total Environ., 346, 231-243, 2005.
Li, W. J. and Shao, L.: Transmission electron microscopy study of aerosol particles from the brown hazes in northern China, J. Geophys. Res., 114, D09302, doi:10.1029/2008JD011285, 2009a.

Li, W. J. and Shao, L. Y.: Observation of nitrate coatings on atmospheric mineral dust particles, Atmos. Chem. Phys., 9, 18631871, doi:10.5194/acp-9-1863-2009, 2009b.

Li, W. J. and Shao, L.: Mixing and water-soluble characteristics of particulate organic compounds in individual urban aerosol particles, J. Geophys. Res., 115, D02301, doi:10.1029/2009JD012575, 2010.

Li, W. J., Anderson, J. R., and Buseck, P. R.: TEM study of aerosol particles from clean and polluted marine boundary layers over the North Atlantic, J. Geophys. Res., 108, 4189, doi:10.1029/2002JD002106, 2003a.

Li, W. J., Pósfai, M., Hobbs, P. V., and Buseck, P. R.: Individual aerosol particles from biomass burning in southern Africa: 2 . Compositions and aging of inorganic particles, J. Geophys. Res., 108, 8484, doi:10.1029/2002JD002310, 2003b.

Li, W. J., Shao, L. Y., and Buseck, P. R.: Haze types in Beijing and the influence of agricultural biomass burning, Atmos. Chem. Phys., 10, 8119-8130, doi:10.5194/acp-10-8119-2010, 2010.

Menon, S., Hansen, J., Nazarenko, L., and Luo, Y.: Climate effects of black carbon aerosols in China, Science, 297, 2250-2253, 2002.

Niemi, J. V., Saarikoski, S., Tervahattu, H., Mäkelä, T., Hillamo, R., Vehkamäki, H., Sogacheva, L., and Kulmala, M.: Changes in background aerosol composition in Finland during polluted and clean periods studied by TEM/EDX individual particle analysis, Atmos. Chem. Phys., 6, 5049-5066, doi:10.5194/acp-6-50492006, 2006.

Pan, Y.-L., Pinnick, R. G., Hill, S. C., Rosen, J. M., and Chang, R. K.: Sing-particle laser-induced-fluorescence spectra of biological and other organic-carbon aerosols in the atmosphere: Measurements at New Haven, Connecticut, and Las Cruces, New Mexico, J. Geophys. Res., 112, D24S19, doi:10.1029/2007JD008741, 2007.

Pósfai, M. and Buseck, P. R.: Nature and climate effects of individual tropospheric aerosol particles, Annu. Rev. Earth Pl. Sci., 38, 17-43, 2010.

Pósfai, M., Simonics, R., Li, J., Hobbs, P. V., and Buseck, P. R.: Individual aerosol particles from biomass burning in sourthern Africa: 1. Compositions and size distributions of carbonaceous particles, J. Geophys. Res., 108, 8483, doi:10.1029/2002JD002291, 2003.

Pósfai, M., Gelencsér, A., Simonics, R., Arató, K., Li, J., Hobbs, P. V., and Buseck, P. R.: Atmospheric tar balls: particles from biomass and biofuel burning, J. Geophys. Res., 109, D06213, doi:10.1029/2003JD004169, 2004.

Ramanathan, M. V. and Garmichael, G.: Global and regional climate changes due to black carbon, Nat. Geosci., 1, 221-227, 2008.

Ramana, M. V., Ramanathan, V., Feng, Y., Yoon, S.-C., Kim, S.W., Carmichael, G. R., and Schauer, J. J.: Warming influenced by the ratio of black carbon to sulphate and the black-carbon source, Nat. Geosci., 3, 542-545, 2010.

Ro, C.-U., Oh, K.-Y. Kim, H., Kim, Y., Lee, C., Kim, K.-H., Kang, C., Osan, J., Hoog, J., Worobiec, A., and Grieken, R. V.: Singleparticle analysis of aerosols at Cheju Island, Korea, using low$\mathrm{Z}$ electron probe $\mathrm{X}$-ray microanalysis: a direct proof of nitrate 
formation from sea salts, Environ. Sci. Technol., 35, 4487-4494, 2001.

Ro, C.-U., Kim, H., Oh, K.-Y., Yea, S., Lee, C., Jang, M., and Grieken, R. V.: Single-particle characterization of urban aerosol particles collected in three Korean cities using low-Z electron probe X-ray microanalysis, Environ. Sci. Technol., 36, 47704776, 2002.

Ro, C.-U., Hwang, H., Kim, H., Chun, Y., and Grjeken, R. V.: Single-particle characterization of four "Asian dust" samples collected in Korea, Using low-Z particle electron probe X-ray microanalysis, Environ. Sci. Technol., 39, 1409-1419, 2005.

Russell, L. M., Maria, S. F., and Myneni, S. C. B.: Mapping organic coatings on atmospheric particles, Geophys. Res. Lett., 29, 1779-1783, 2002.

Semeniuk, T. A, Wise, M. E., Martin, S. T., Russell, L. M., and Buseck, P. R.: Water uptake characteristics of individual atmospheric particles having coatings, Atmos. Environ., 41, 62256235, 2007.

Sun, J. and Ariya, P. A.: Atmospheric organic and bio-aerosols as cloud condensation nuclei $(\mathrm{CCN})$ : A review, Atmos. Environ., 40, 795-820, 2006.

Sun, Y., Zhuang, G., Tang, A., Wang, Y., and An, Z.: Chemical characteristics of $\mathrm{PM}_{2.5}$ and $\mathrm{PM}_{10}$ in haze-fog episodes in Beijing, Environ. Sci. Technol., 40, 3148-3155, 2006.

Utsunomiya, S., Jensen, K. A., Keeler, G. J., and Ewing, R. C.: Uraninite and fullerene in atmospheric particulates, Environ. Sci. Technol., 36, 4943-4947, 2002.

Utsunomiya, S., Jensen, K. A., Keeler, G. J., and Ewing, R. C.: Direct identification of trace metals in fine and ultrafine particles in the Detroit urban atmosphere, Environ. Sci. Technol., 38, 22892297, 2004.

Varutbangkul, V., Brechtel, F. J., Bahreini, R., Ng, N. L., Keywood, M. D., Kroll, J. H., Flagan, R. C., Seinfeld, J. H., Lee, A., and Goldstein, A. H.: Hygroscopicity of secondary organic aerosols formed by oxidation of cycloalkenes, monoterpenes, sesquiterpenes, and related compounds, Atmos. Chem. Phys., 6, 23672388, doi:10.5194/acp-6-2367-2006, 2006.
Vernooij, M. G. C., Mohr, M., Tzvetkov, G., Zelenay, V., Huthwelker, T., Kaegi, R., Gehrig, R., and Grobety, B.: On source identification and alteration of single diesel and wood smoke soot particles in the atmosphere: An X-ray microspectroscopy study, Environ. Sci. Technol., 43, 5339-5344, 2009.

Viktória, K. K, Mihály, P., and János, L.: Nanostructure of atmospheric soot particles, Atmos. Environ., 40, 5533-5542, 2006.

Wittmaack, K., Wehnes, H., Heinzzmann, U., and Agerer, R.: An overview on bioaerosols viewed by scanning electron microscopy, Sci. Total Environ., 346, 244-255, 2005.

Zhang, D., Shi, G.-Y., Iwasaka, Y., and Hu, M.: Mixture of sulphate and nitrate in coastal atmospheric aerosols: individual particle studies in Qingdao $\left(36^{\circ} 4^{\prime} \mathrm{N}, 120^{\circ} 21^{\prime} \mathrm{E}\right)$, China, Atmos. Environ., 34, 2669-2679, 2000.

Zhang, R.: Atmospheric new particle formation enhanced by organic acids, Science, 304, 1487-1490, 2004a.

Zhang, R., Khalizov, A. F., Pagels, J., Zhang, D., Xue, H. X., and McMurry, P. H.: Variability in morphology, hygroscopicity, and optical properties of soot aerosols during atmospheric processing, P. Natl. Acad. Sci. USA, 105, 10291-10296, 2008.

Zhang, Y., Yu, Q., Ma, W., and Chen, L.: Atmospheric deposition of inorganic nitrogen to the eastern China seas and its implications to marine biogeochemistry, J. Geophys. Res., 115, D00K10, doi:10.1029/2009JD012814, 2010.

Zhou, X., Gao, J., Wang, T., Wu, W., and Wang, W.: Measurement of black carbon aerosols near two Chinese megacities and the implications for improving emission inventories, Atoms. Environ., 43, 3918-3924, 2009.

Zuberi, B., Johnson, K. S., Aleks, G. K., Molina, L. T., Molina, M. J., and Laskin, A.: Hydrophilic properties of aged soot, Geophys. Res. Lett., 32, L01807, doi:10.1029/2004GL021496, 2005. 